\title{
Au Nanorings with Intertwined Triple Rings
}

Sungjae Yoo ${ }^{1}$, Sungeun Go ${ }^{1}$, Jiwoong Son ${ }^{2}$, Jeongwon Kim ${ }^{1}$, Soohyun Lee ${ }^{1}$, MohammadNavid Haddadnezhad ${ }^{1}$, Hajir Hilal ${ }^{1}$, Jae-Myoung $\mathrm{Kim}^{2}$, Jwa-Min $\mathrm{Nam}^{2}$, and Sungho Park*1

${ }^{1}$ Department of Chemistry, Sungkyunkwan University, Suwon 440-746, South Korea.

${ }^{2}$ Department of Chemistry, Seoul National University, Seoul 08826, South Korea.

*Corresponding author. Email: spark72@skku.edu

This PDF file includes:

Materials and instruments

Synthetic method

Figures S1 to S12 


\section{Table of Contents:}

Materials and instruments............................................................

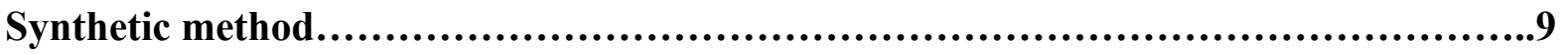

Figure S1. Schematic illustration of the rational multi-stepwise synthetic process including five chemical toolkits: selective etching of Au (step 1, 4 and 7), overgrowth of Au (step 2), selective growth of Pt (step 3 and 6), well-faceted growth of Au (step 5) and concentric

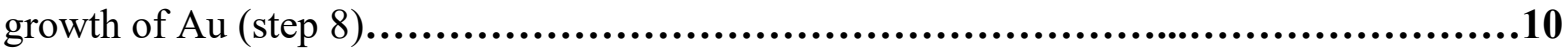

Figure S2. SEM image of (A) triangular Au nanoplates, (B) circular Au nanoplates, (C) hexagonal Au nanoplates, and (D) hexagonal Au@Pt nanoplates............................11

Figure S3. Schematic illustration of the mechanism of distinctive chemical toolkits..........12

Figure S4. Analysis the composition of ANITs through STEM EDS image mapping..........13

Figure S5. Controlling the growth pattern of $\mathrm{Au}$ on the PtAu nanorings by controlling experimental parameters such as $\mathrm{pH}$ of the reaction solution and halide ions (I-, Br-, Cl-). (A) FE-SEM images of morphology of $\mathrm{Pt} @ \mathrm{Au}$ nanorings as function of $\mathrm{pH}$ of the reaction solution and halide ions. (B) Summarized experimental conditions for growth pattern control

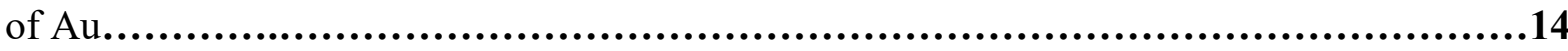

Figure S6. Controlling the morphology of (A to C) Pt@Au nanorings as function of the ratio of $[\mathrm{Au}] /[\mathrm{Ag}]$ ratio.....................................................................15

Figure S7. Concentric growth of $\mathrm{Au}$ on the (A) PtAu nanorings. (B to D) thickness of $\mathrm{Pt} @ \mathrm{Au}$ nanorings was controlled as a function of the amount of $\mathrm{Au}$ in the reaction solution. .16

Figure S8. (A and D) Dimension information, (B and E) SEM images, and (C and F) UVvis-NIR spectra of Au double nanorings with different geometries............................17

Figure S9. Single-particle SERS signals of double nanorings without (A) light absorber and (B) gap controller. .18

Figure S10. Analysis of the surface composition of ANITs (corresponding to Figure 3I) through X-ray photoelectron spectroscopy (XPS).

Figure S11. SEM images of (A) PtAu nanorings, (B) Pt@Au nanorings with well-faceted growth, (C) Pt@Au@Pt nanorings, (D) Pt@Au@Pt@Au nanoplates, (E) Pt@Au@Pt@Au@Pt nanoplates......................................................................20

Figure S12. (A) Synthetic process for triangular PtAu triple nanorings, (B) triangular PtAu nanorings, (C) triangular Pt@Au nanorings with eccentric growth pattern, (D) triangular 
Pt@Au@Pt nanorings, (E) triangular Pt@Au@Pt@Au nanoplates, (F) triangular Pt@Au@Pt@Au nanoplates, and (G) low magnification SEM image and zoomed-in SEM image of triangular PtAu triple nanorings................................................21

\section{Experimental Section:}

\section{Materials}

Hydrogen tetrachloroaurate (III) hydrate $\left(\mathrm{HAuCl}_{4} \cdot \mathrm{nH}_{2} \mathrm{O}, 99 \%\right)$ and hydrogen hexachloroplatinate (IV) hydrate $\left(\mathrm{H}_{2} \mathrm{PtCl}_{6} \cdot \mathrm{nH}_{2} \mathrm{O}\right.$, 99\%) were purchased from Kojima. Sodium borohydride $\left(\mathrm{NaBH}_{4}, 98 \%\right)$ and silver nitrate $\left(\mathrm{AgNO}_{3}, 99.8 \%\right)$ were purchased from Junsei. Sodium iodide (NaI, 99.5\%) and L-ascorbic acid $\left(\mathrm{C}_{6} \mathrm{H}_{8} \mathrm{O}_{6}, 99.5 \%\right)$ were supplied by Sigma Aldrich. Hydrochloric acid $(\mathrm{HCl}, 35 \%)$ and sodium hydroxide $(\mathrm{NaOH}, 98 \%)$ were purchased from Samchun. Cetyltrimethylammonium bromide (CTAB, $\mathrm{C}_{19} \mathrm{H}_{42} \mathrm{BrN}, 95 \%$ ) was purchased from Sigma-Aldrich. Cetyltrimethylammonium chloride (CTAB, $\mathrm{C}_{19} \mathrm{H}_{42} \mathrm{BrCl}, 95 \%$ ) was purchased from Tokyo Chemical Industry. All chemical materials were dissolved in distilled water (18.2 M $\Omega$ ) prepared using a water purification system (Milli-Q, Millipore).

\section{Characterization}

Field emission scanning electron microscopy (FESEM) images were obtained using JSM7100F and JSM-7800F instruments (JEOL). JEM-2100F and JEM-ARM 200F instruments (JEOL) were used to acquire transmission electron microscopy (TEM) images. UV-vis-NIR absorption spectra were acquired using a spectrophotometer (Shimadzu UV-3600). Raman spectra and images were recorded on Raman microscope (Ntegra, NT-MDT). A NX10 instrument (Park systems) was used to acquire AFM images and height profiles. X-ray diffraction (XRD) patterns of the nanostructures were characterized using a Rigaku Ultima IV. The electrochemical measurements were performed using an Auto Lab AUT12.

\section{Methods}

\section{Synthesis of Gold Triangular Nanoplates}

Gold triangular nanoplates were prepared from $5 \mathrm{~nm}$ sphere seeds by means of a three-step seed-mediated method with iodide ions. First, $500 \mu \mathrm{L}$ of a $20 \mathrm{mM} \mathrm{HAuCl}{ }_{4} \cdot 3 \mathrm{H}_{2} \mathrm{O}, 1 \mathrm{~mL}$ of a $10 \mathrm{mM}$ of sodium citrate, and $1 \mathrm{~mL}$ of a $100 \mathrm{mM} \mathrm{NaBH}_{4}$ (ice-cold) were added to $36.5 \mathrm{~mL}$ of 
deionized water under vigorous stirring. Three labeled flasks were used to prepare the triangular nanoplates. A mixture of $108 \mathrm{~mL}$ of $0.05 \mathrm{M} \mathrm{CTAB}$ and $54 \mu \mathrm{L}$ of $0.1 \mathrm{M} \mathrm{NaI}$ was divided to three containers, which were labeled 1, 2, and 3. Next, $9 \mathrm{~mL}$ of each mixture was added to containers 1 and 2, and the remaining $90 \mathrm{~mL}$ to container 3 . A mixture of $125 \mu \mathrm{L}$ of $20 \mathrm{mM} \mathrm{HAuCl}{ }_{4} \cdot 3 \mathrm{H}_{2} \mathrm{O}, 50 \mu \mathrm{L}$ of $100 \mathrm{mM} \mathrm{NaOH}$, and $50 \mu \mathrm{L}$ of $100 \mathrm{mM}$ ascorbic acid (AA) was then added to containers 1 and 2. A mixture of $1.25 \mathrm{~mL}$ of $20 \mathrm{mM} \mathrm{HAuCl}{ }_{4} \cdot 3 \mathrm{H}_{2} \mathrm{O}, 0.5$ $\mathrm{mL}$ of $100 \mathrm{mM} \mathrm{NaOH}$, and $0.5 \mathrm{~mL}$ of $100 \mathrm{mM}$ AA was added to container 3 . A total of $1 \mathrm{~mL}$ of the seed solution was added to container 1 under mild shaking, followed by the addition of $1 \mathrm{~mL}$ of the container 1 solution to container 2 . After gentle shaking, the solution in container 2 was added to container 3 .

\section{Synthesis of Gold Circular Nanoplates}

Gold circular nanoplates were prepared after etching the Au triangular nanoplates through a comproportionation reaction of $\mathrm{Au}$. One and a half milliliters of a mixture of $10 \mathrm{~mL}$ of $0.1 \mathrm{M}$ $\mathrm{CTAB}$ and $250 \mu \mathrm{L}$ of a $20 \mathrm{mM} \mathrm{HAuCl}{ }_{4} \cdot 3 \mathrm{H}_{2} \mathrm{O}$ was added to $10 \mathrm{~mL}$ (optical density is 1.2 , quadruple mode) of an aqueous solution of triangular nanoplates. The triangular nanoplates were etched via gold ions in an isothermal oven at $30{ }^{\circ} \mathrm{C}$. After $1 \mathrm{~h}$, the triangular nanoplates became gold nanodisks. Residual gold ions were removed by means of centrifugation at 8000 rpm for $20 \mathrm{~min}$.

\section{Synthesis of Gold Hexagonal Nanoplates}

$\mathrm{Au}$ hexagonal nanoplates were prepared by growth of $\mathrm{Au}$ on the $\mathrm{Au}$ circular nanoplates. $\mathrm{Au}$ hexagonal nanoplates were obtained by mixing $400 \mu \mathrm{L}$ of $0.1 \mathrm{M}$ aqueous CTAB solution with $0.1 \mathrm{M}$ iodide, $50 \mu \mathrm{L}$ of $20 \mathrm{mM} \mathrm{HAuCl}_{4}, 50 \mu \mathrm{L}$ of $100 \mathrm{mM}$ ascorbic acid and $6 \mathrm{~mL}$ of an aqueous solution of circular gold nanoplates. The optical density (dipole mode) of circular nanodisks was adjusted to 1.2 with water prior to mixing. The mixture was reacted by holding it in an isothermal oven at $30^{\circ} \mathrm{C}$ for $1 \mathrm{~h}$.

\section{Synthesis of 2D PtAu Single Nanoframes}

In the presence of iodide ions $(50 \mu \mathrm{M}), 20 \mathrm{~mL}$ of $0.05 \mathrm{M}$ CTAB, $4 \mathrm{~mL}$ of redispersed $\mathrm{Au}$ nanoplates (optical densities of 1.2 for disks (dipole), 1.2 for prisms (quadruple), and 1.0 for 
hexagons (dipole)), $10 \mu \mathrm{L}$ (disk), $12.5 \mu \mathrm{L}$ (triangles), and $20 \mu \mathrm{L}$ (hexagons) in a $2 \mathrm{mM}$ $\mathrm{AgNO}_{3}$, and $480 \mu \mathrm{L}$ of $0.1 \mathrm{M} \mathrm{AA}$ were added to a vial. The mixture was kept at $70{ }^{\circ} \mathrm{C}$. After $1 \mathrm{~h}, 480 \mu \mathrm{L}$ of $0.1 \mathrm{M} \mathrm{HCl}$ and $100 \mu \mathrm{L}$ (disks), $125 \mu \mathrm{L}$ (triangles), and $200 \mu \mathrm{L}$ (hexagons) of a $2 \mathrm{mM}$ aqueous $\mathrm{H}_{2} \mathrm{PtCl}_{6}$ solution were added to the mixture with gentle shaking. The mixture was kept at $70{ }^{\circ} \mathrm{C}$ for $4 \mathrm{~h}$. After this reaction, the sample was centrifuged, and the supernatant was removed and redispersed in a mixture of $5 \mathrm{~mL}$ of $0.05 \mathrm{M} \mathrm{CTAB}$ and $2.5 \mu \mathrm{L}$ of $0.1 \mathrm{M}$ aqueous NaI solution. Next, $500 \mu \mathrm{L}$ of a $2 \mathrm{mM}$ aqueous $\mathrm{HAuCl}_{4}$ was added to etch the $\mathrm{Au} @ \mathrm{Pt}$ nanoplates. This etching process was carried out for $1 \mathrm{~h}$ in a $50{ }^{\circ} \mathrm{C}$ oven and was followed by centrifugal washing $(8000 \mathrm{rpm} \times 20 \mathrm{~min})$.

\section{Well-Faceted Growth of Gold on the PtAu Nanoring with Circular, Hexagonal, and Triangular Shapes}

Pt@Au nanorings with a well-faceted growth pattern were synthesized by reducing gold ions in the presence of $\mathrm{Cl}^{-}$ions. After etching inner $\mathrm{Au}$, PtAu nanorings with circular and hexagonal shape were redispersed in deionized water, and $500 \mu \mathrm{L}$ of a solution of PtAu single nanorings were stabilized by adding a mixture of $1 \mathrm{~mL}$ of $0.2 \mathrm{M}$ CTAC aqueous solution. Subsequently, a $2 \mathrm{mM} \mathrm{AgNO}_{3}$ solution was added to the PtAu single nanorings solution in the following volumes: 40, 50, and $65 \mu \mathrm{L}$ (hexagons), 20, 30, and $45 \mu \mathrm{L}$ (disks), then $100 \mathrm{mM}$ AA was added to the resulting mixtures in a volume ratio of 1(100 mM AA):10 $\left(2 \mathrm{mM} \mathrm{AgNO}_{3}\right)$, and finally, $2 \mathrm{mM} \mathrm{HAuCl}_{4}$ solution was added to the PtAu single nanorings solution in the following volumes: 40,50 , and $65 \mu \mathrm{L}$ (hexagons), 20, 30, and $45 \mu \mathrm{L}$ (disks). The resulting reduction reaction was monitored by means of extinction spectrum measurements. Residual ions were removed by centrifugation at $8000 \mathrm{rpm}$ for $20 \mathrm{~min}$.

\section{Synthesis of Pt@Au@Pt Nanorings}

Pt@Au@Pt nanorings were obtained by well-faceted growth of Au on the PtAu nanorings with circular shape and selective deposition of Pt. In the presence of iodide ions $(50 \mu \mathrm{M}), 1$ $\mathrm{mL}$ of $0.05 \mathrm{M} \mathrm{CTAB}, 500 \mu \mathrm{L}$ of redispersed Pt@Au nanorings with well-faceted growth, 2.8 $\mu \mathrm{L}$ of $2 \mathrm{mM} \mathrm{AgNO}_{3}$, and $48 \mu \mathrm{L}$ of $0.1 \mathrm{M} \mathrm{AA}$ were added to a vial. The mixture was kept at $70{ }^{\circ} \mathrm{C}$. After $1 \mathrm{~h}, 48 \mu \mathrm{L}$ of $0.1 \mathrm{M} \mathrm{HCl}$ and $28 \mu \mathrm{L}$ of $2 \mathrm{mM} \mathrm{H}_{2} \mathrm{PtCl}_{6}$ were added to the mixture with gentle shaking. The mixture was kept at $70^{\circ} \mathrm{C}$ for $4 \mathrm{~h}$. 


\section{Synthesis of Pt@Au@Pt Nanorings with Hexagonal and Triangular Shapes}

Pt@Au@Pt nanorings were obtained by well-faceted growth of Au on the PtAu nanorings with circular shape and selective deposition of Pt. In the presence of iodide ions $(50 \mu \mathrm{M}), 1$ $\mathrm{mL}$ of $0.05 \mathrm{M} \mathrm{CTAB}, 500 \mu \mathrm{L}$ of redispersed Pt@Au nanorings with triangular and hexagonal shapes, $2.8 \mu \mathrm{L}$ (for triangular shape), $2.8 \mu \mathrm{L}$ (for hexagonal shape) of $2 \mathrm{mM} \mathrm{AgNO}$, and 48 $\mu \mathrm{L}$ of $0.1 \mathrm{M}$ AA were added to a vial. The mixture was kept at $70^{\circ} \mathrm{C}$. After $1 \mathrm{~h}, 48 \mu \mathrm{L}$ of 0.1 $\mathrm{M} \mathrm{HCl}$ and $28 \mu \mathrm{L}$ (for triangular shape), $28 \mu \mathrm{L}$ (for hexagonal shape) of $2 \mathrm{mM} \mathrm{H}_{2} \mathrm{PtCl}_{6}$ were added to the mixture with gentle shaking. The mixture was kept at $70{ }^{\circ} \mathrm{C}$ for $4 \mathrm{~h}$.

\section{Well-Faceted Growth of Gold on the Pt@Au@Pt Nanorings}

Pt@Au@Pt@Au nanoplates with a well-faceted growth pattern were obtained by reducing gold ions in the presence of $\mathrm{Cl}^{-}$ions. First, $500 \mu \mathrm{L}$ of Pt@Au@Pt nanorings dispersed in 0.1 M CTAC, $45 \mu \mathrm{L}$ of $2 \mathrm{mM} \mathrm{AgNO}_{3}, 4 \mu \mathrm{L}$ of $0.1 \mathrm{M} \mathrm{AA}$ was added to $1.5 \mathrm{ml}$ Eppendorf tube. Then, $45 \mu \mathrm{L}$ of $2 \mathrm{mM} \mathrm{HAuCl}_{4}$ was added. The reaction solution was kept in an isothermal oven at 50 C. After 1 h, the Pt@Au@Pt@Au nanoplates with a well-faceted growth pattern were obtained. Residual gold ions were removed by means of centrifugation at 10,000 rpm for $5 \mathrm{~min}$.

\section{Well-Faceted Growth of Gold on the Pt@Au@Pt Nanorings with a Triangular Shape}

Pt@Au@Pt@Au nanoplates with a well-faceted growth pattern having a triangular shape were synthesized by reducing gold ions in the presence of $\mathrm{Cl}^{-}$ions. First, $\mathrm{Pt} @ \mathrm{Au} @ \mathrm{Pt}$ nanorings with a triangular shape were prepared following our previous paper (ref 1). Then, $250 \mu \mathrm{L}$ of Pt@Au@Pt with a prism shape dispersed in 0.1 M CTAC, $65 \mu \mathrm{L}$ of 2mM $\mathrm{AgNO}_{3}$, and $6.5 \mu \mathrm{L}$ of $0.1 \mathrm{M}$ AA was added to $1.5 \mathrm{ml}$ Eppendorf tube. Then, $65 \mu \mathrm{L}$ of $2 \mathrm{mM} \mathrm{HAuCl}_{4}$ was added. The reaction solution was kept in an isothermal oven at $50{ }^{\circ} \mathrm{C}$. After $1 \mathrm{~h}$, Pt@Au@Pt@Au nanoplates with prism shapes were obtained. Residual gold ions were removed by means of centrifugation at $10,000 \mathrm{rpm}$ for $5 \mathrm{~min}$.

\section{Synthesis of Pt@Au@Pt@Au@Pt Nanoplates}

Pt@Au@Pt@Au@Pt nanoplates with hexagonal shape were obtained by selective deposition of Pt. In the presence of iodide ions $(50 \mu \mathrm{M}), 1 \mathrm{~mL}$ of $0.05 \mathrm{M} \mathrm{CTAB}, 500 \mu \mathrm{L}$ of redispersed 
Pt@Au@Pt@Au nanoplates, $2.8 \mu \mathrm{L}$ of 2 mM AgNO 3 , and $48 \mu \mathrm{L}$ of 0.1 M AA were added to a vial. The mixture was kept at $70{ }^{\circ} \mathrm{C}$. After $1 \mathrm{~h}, 48 \mu \mathrm{L}$ of $0.1 \mathrm{M} \mathrm{HCl}$ and $28 \mu \mathrm{L}$ of $2 \mathrm{mM}$ $\mathrm{H}_{2} \mathrm{PtCl}_{6}$ were added to the mixture with gentle shaking. The mixture was kept at $70{ }^{\circ} \mathrm{C}$ for $4 \mathrm{~h}$.

\section{Synthesis of Pt@Au@Pt@Au@Pt Nanoplates with a Triangular Shape}

Pt@Au@Pt@Au@Pt nanoplates with a Triangular shape were obtained by selective deposition of Pt. In the presence of iodide ions $(50 \mu \mathrm{M}), 1 \mathrm{~mL}$ of $0.05 \mathrm{M}$ CTAB, $250 \mu \mathrm{L}$ of redispersed Pt@Au@Pt@Au nanoplates with triangular shape, $2.6 \mu \mathrm{L}$ of 2 mM AgNO 3 , and $48 \mu \mathrm{L}$ of $0.1 \mathrm{M}$ AA were added to a vial. The mixture was kept at $70^{\circ} \mathrm{C}$. After $1 \mathrm{~h}, 48 \mu \mathrm{L}$ of $0.1 \mathrm{M} \mathrm{HCl}$ and $26 \mu \mathrm{L}$ of $2 \mathrm{mM} \mathrm{H}_{2} \mathrm{PtCl}_{6}$ were added to the mixture with gentle shaking. The mixture was kept at $70{ }^{\circ} \mathrm{C}$ for $4 \mathrm{~h}$.

\section{Synthesis of PtAu Nanorings with Intertwined Triple Rings (Hexagonal outer shape)}

PtAu nanorings with intertwined triple rings having hexagonal shape were synthesized after etching inner Au domain of Pt@Au@Pt nanorings with a hexagonal shape. First, $20 \mu \mathrm{L}$ of 2 $\mathrm{mM}$ aqueous $\mathrm{HAuCl}_{4}$ was added to the reaction solution. The reaction solution contained 500 $\mu \mathrm{L}$ of Pt@Au@Pt nanorings and 1 mL CTAB with $50 \mu \mathrm{M}$ iodide. This etching process was carried out for $1 \mathrm{~h}$ in a $50{ }^{\circ} \mathrm{C}$ oven and was followed by centrifugal washing ( $8000 \mathrm{rpm} \times 20$ $\min )$.

\section{Synthesis of PtAu Nanorings with Intertwined Triple Rings (Triangular shape)}

Triangular-shaped PtAu nanorings with intertwined triple-rings were synthesized after etching inner Au domain of Pt@Au@Pt@Au@Pt nanoplates with a triangular shape. First, $60 \mu \mathrm{L}$ of $2 \mathrm{mM} \mathrm{HAuCl}_{4}$ was added to etch the Pt@Au@Pt nanorings. This etching process was carried out for $1 \mathrm{~h}$ in a $50{ }^{\circ} \mathrm{C}$ oven and was followed by centrifugal washing ( $8000 \mathrm{rpm} \times$ $20 \mathrm{~min})$.

\section{Synthesis of PtAu Tetra-Nanorings}

PtAu nanorings with intertwined tetra-rings were synthesized after etching the inner $\mathrm{Au}$ domain of Pt@Au@Pt@Au@Pt nanoplates with hexagonal shapes. First, $50 \mu \mathrm{L}$ of 2 mM aqueous $\mathrm{HAuCl}_{4}$ was added to etch the Pt@Au@Pt nanorings. This etching process was 
carried out for $1 \mathrm{~h}$ in a $50{ }^{\circ} \mathrm{C}$ oven and was followed by centrifugal washing $(8000 \mathrm{rpm} \times 20$ $\min )$.

\section{Electric Field Simulations}

For quantitative explanation of the optical response of the structures, the finite element method was using the commercial software COMSOL Multiphysics. Each Au nanoring in double-ring and triple-ring structures was modelled as a torus. To model the structures realistically, each ring was connected via bridges. The dielectric function of gold and water was from Johnson and Christy (ref 2) and $1.33^{2}$, respectively. The propagating direction of the electromagnetic wave was along the axis of the rings, which was the experimental condition of the single-particle SERS measurement.

\section{Single particle SERS Measurement}

SERS measurements were conducted using a Raman microscope (Ntegra, NT-MDT) equipped with an inverted optical microscope (IX 73, Olympus). A dichroic mirror directs the excitation laser beam into the oil-immersion objective (UPlanSApo, 100×, 1.4 numerical aperture), which focuses the beam to a diffraction-limited spot $(\sim 2 \mu \mathrm{m})$ on the upper surface of the cover glass slip. Photomultiplier tube images were obtained using a piezoelectric $\mathrm{x}, \mathrm{y}$ sample scanner to identify nanoparticles. The SERS spectra were acquired with a $785 \mathrm{~nm}$ laser $(170 \mu \mathrm{W})$ for $10 \mathrm{~s}$. The signals were detected by a charge-coupled device detector $(1024$ $\times 256$ pixels; Peltier cooled to $-70{ }^{\circ} \mathrm{C}$, Andor Newton DU920P BEX2-DD). After analysis, FESEM images of the samples were obtained by Pt layer deposition using an Ar plasma sputter-coater (Cressington 108 auto) with a current level of $20 \mathrm{~mA}$ for $60 \mathrm{~s}$ on the slide glass.

\section{Calculation of Enhancement Factor}

The enhancement factor of Raman signals was based on the following equation:

$E F=\frac{I_{\text {sers }}}{I_{\text {bulk }}} \times \frac{N_{\text {bulk }}}{N_{\text {AuNPs }}}$

$\mathrm{I}_{\text {sers }}$ and $\mathrm{I}_{\text {bulk }}$ are the Raman intensities of 2-naphthalenethiol (2-NTT) for surface adsorption and solution samples, respectively. $\mathrm{N}_{\text {bulk }}$ is the number of 2-naphthalenethiol molecules in the volume for the normal Raman signals, and $\mathrm{N}_{\text {sers }}$ is the number of 2-naphthalenethiol 
molecules absorbed on the Ag double nanoring for the SERS signal. The SERS peak, which is a ring stretching mode at $\sim 1380 \mathrm{~cm}^{-1}$, was chosen for the EF calculation.

$$
A=\left(\frac{V \times d}{M_{w}}\right) \times N_{A}=\left(\frac{\pi \times r^{2} \times h \times d}{M_{w}}\right) \times N_{A}=2.67 \times 10^{12}
$$

$\mathrm{N}_{\text {bulk }}$ was calculated using the following equation:

Here, $\mathrm{V}$ is the excitation volume of the 2-NTT substrate, $\mathrm{d}$ is the density of 2-NTT (1.2 $\left.\mathrm{g} / \mathrm{cm}^{3}\right)$, Mw is the molecular weight of 2-NTT (160.23 $\left.\mathrm{g} / \mathrm{mol}\right)$, NA is Avogadro's number $\left(6.02 \times 10^{23} \mathrm{~mol}^{-1}\right), \mathrm{r}$ is the radius of the laser beam $(\sim 2 \mu \mathrm{m})$, and $\mathrm{h}$ is the focal depth of the laser $(\sim 47 \mu \mathrm{m})$.

$\mathrm{N}_{\text {sers }}$ was calculated using the following equation:

$N_{\text {sers }}=A \times D \times N_{A}=7.7 \times 10^{4}$ (for ANIT), $10.3 \times 10^{4}$ (for $\mathrm{Au}$ double nanorings with outer and core rings), $5.3 \times 10^{4}$ (for Au double nanorings with middle and core rings)

Here, $\mathrm{A}$ is the SERS active area of the nanostructures, which was measured as the entire surface area, (ANIT: $\left(3.1 \times 10^{-10} \mathrm{~cm}^{2}\right)$, Au double nanorings with outer and core rings $(4.2$ $\left.\times 10^{-10} \mathrm{~cm}^{2}\right), \mathrm{Au}$ double nanorings with middle and core rings $\left(2.1 \times 10^{-10} \mathrm{~cm}^{2}\right)$, D is the estimated coverage of 2-NTT molecules in a single-assembled monolayer on $\mathrm{Au}$ ( $4.0 \times$ $\left.10^{-10} \mathrm{~mol} / \mathrm{cm}^{2}\right)$.

\section{References}

1) Yoo, S.; Kim, J.; Choi, S.; Park, D.; Park, S., Two-dimensional nanoframes with dual rims. Nat Commun. 2019, 10, 5789.

2) Johnson, P. B.; Christy, R. W., Physical Review B, 1972, 6, 4370-4379 


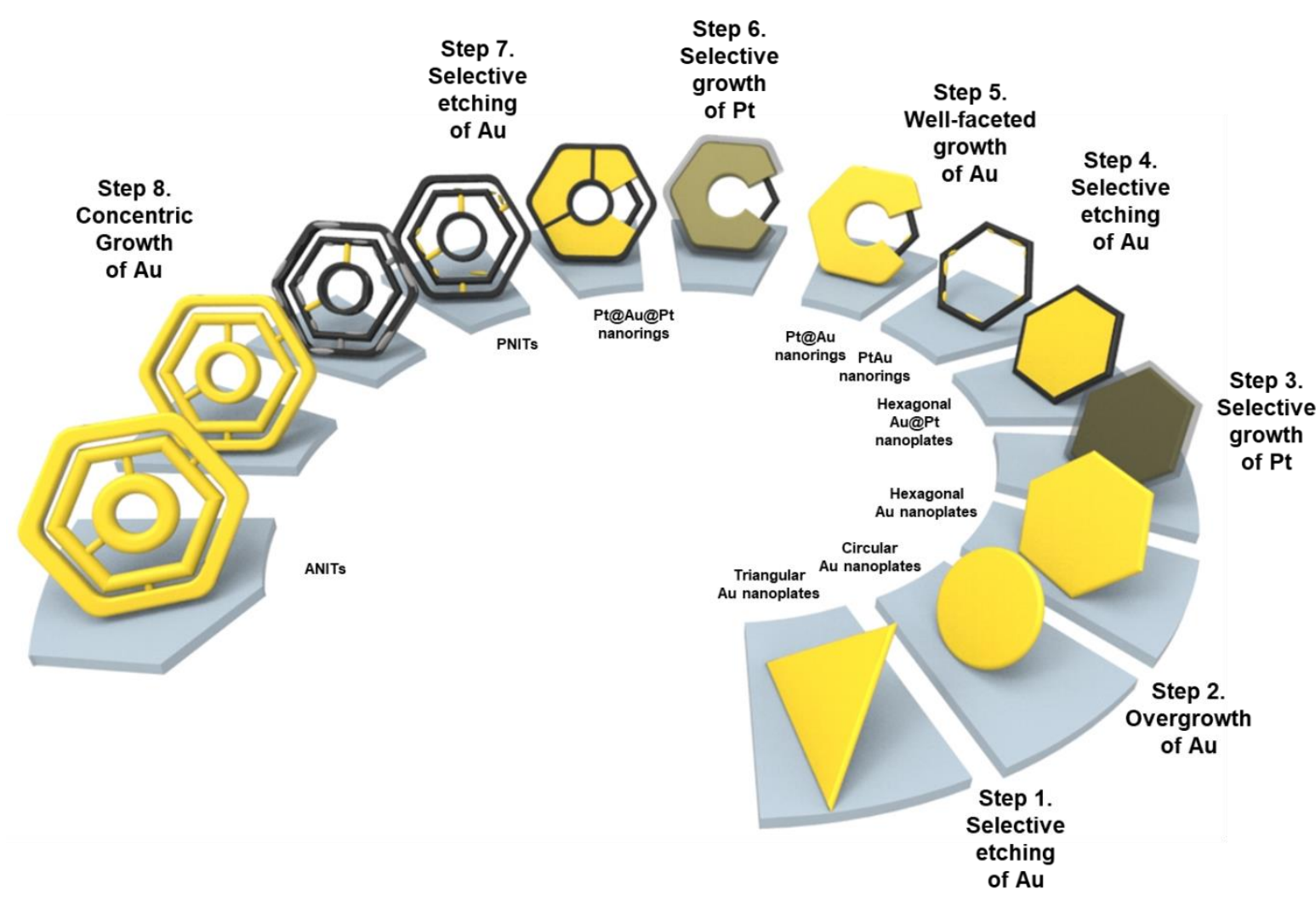

Figure S1. Schematic illustration of the rational multi-stepwise synthetic process including five chemical toolkits: selective etching of $\mathrm{Au}$ (step 1, 4 and 7), overgrowth of $\mathrm{Au}$ (step 2), selective growth of Pt (step 3), well-faceted growth of $\mathrm{Au}$ (step 5) and concentric growth of Au (step 8). 


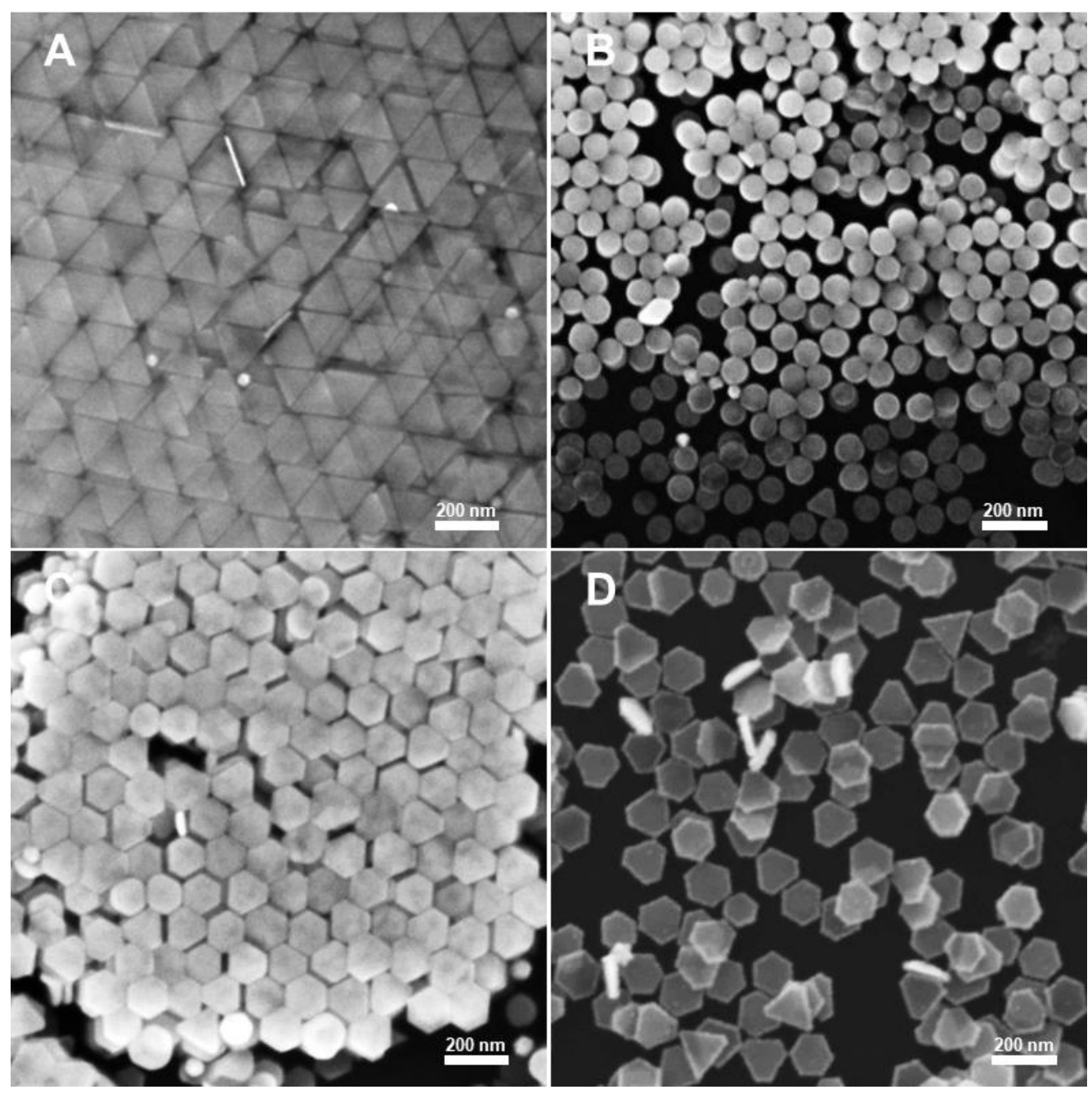

Figure S2. SEM image of (A) triangular Au nanoplates, (B) circular Au nanoplates, (C) hexagonal Au nanoplates, and (D) hexagonal Au@Pt nanoplates. 


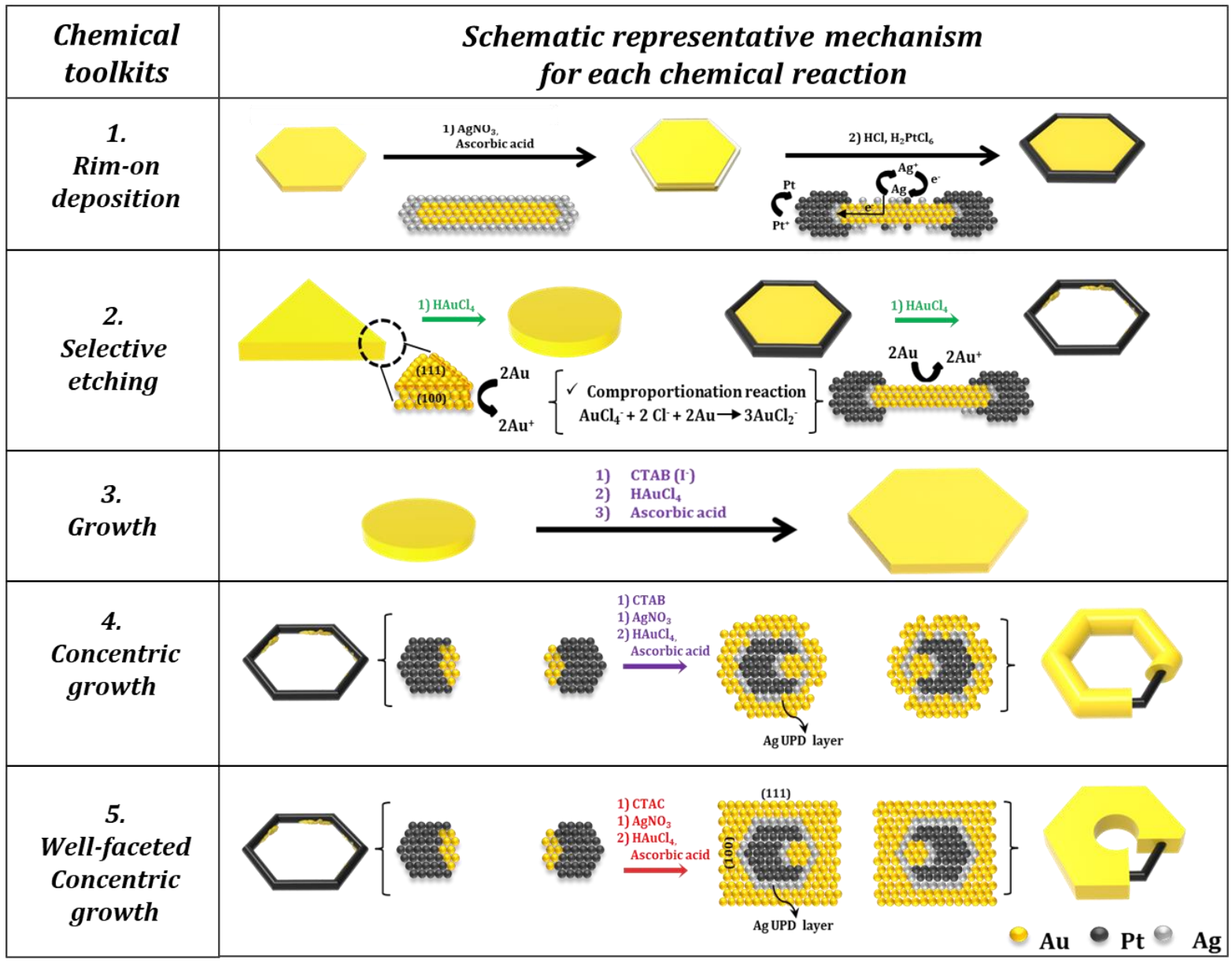

Figure S3. Schematic illustration of mechanisms of distinctive chemical toolkits. 
Electron Image 1
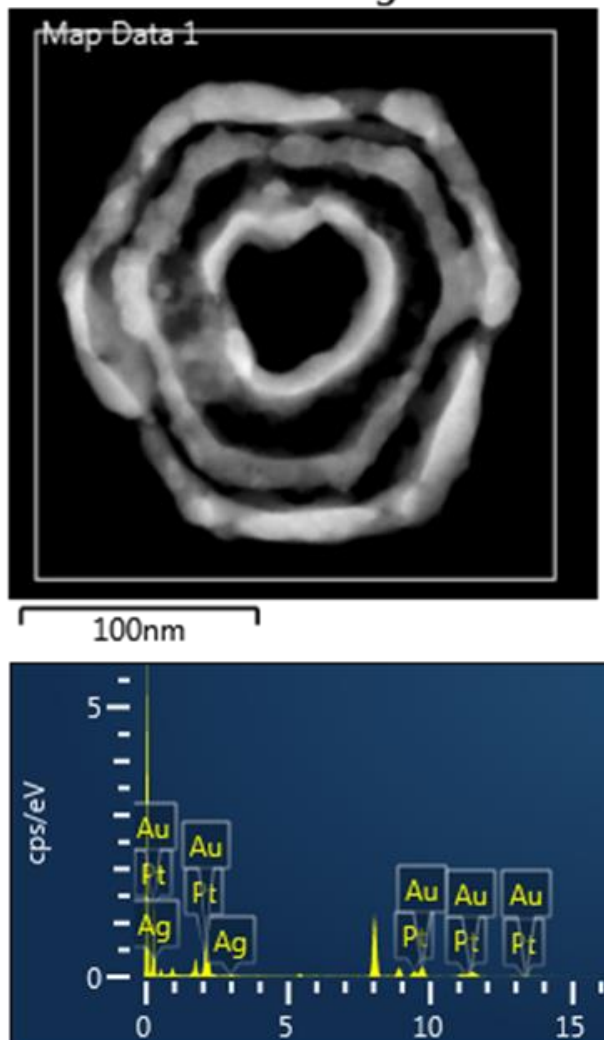

EDS Layered Image 1

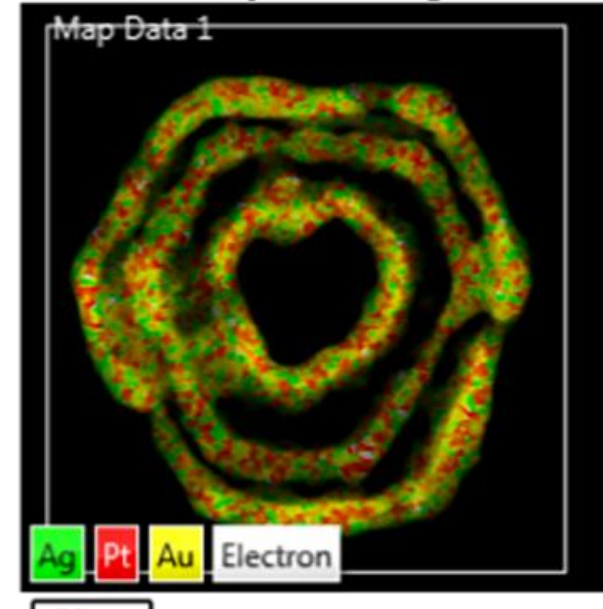

$\longdiv { 5 0 \mathrm { nm } }$

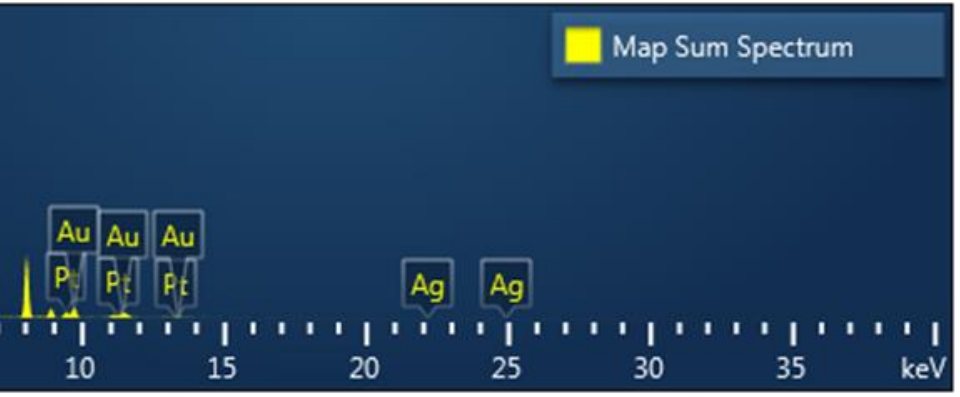

\begin{tabular}{|c|c|c|c|c|}
\hline Element & Line Type & Wt\% & Wt\% Sigma & Atomic \% \\
\hline $\mathrm{Ag}$ & L series & 3.40 & 0.71 & 6 \\
\hline $\mathrm{Pt}$ & L series & 33.30 & 1.06 & 33 \\
\hline $\mathrm{Au}$ & L series & 63.30 & 1.12 & 61 \\
\hline Total: & & 100.00 & & 100.0 \\
\hline
\end{tabular}

Figure S4. Analysis the composition of ANITs through STEM EDS image mapping. 

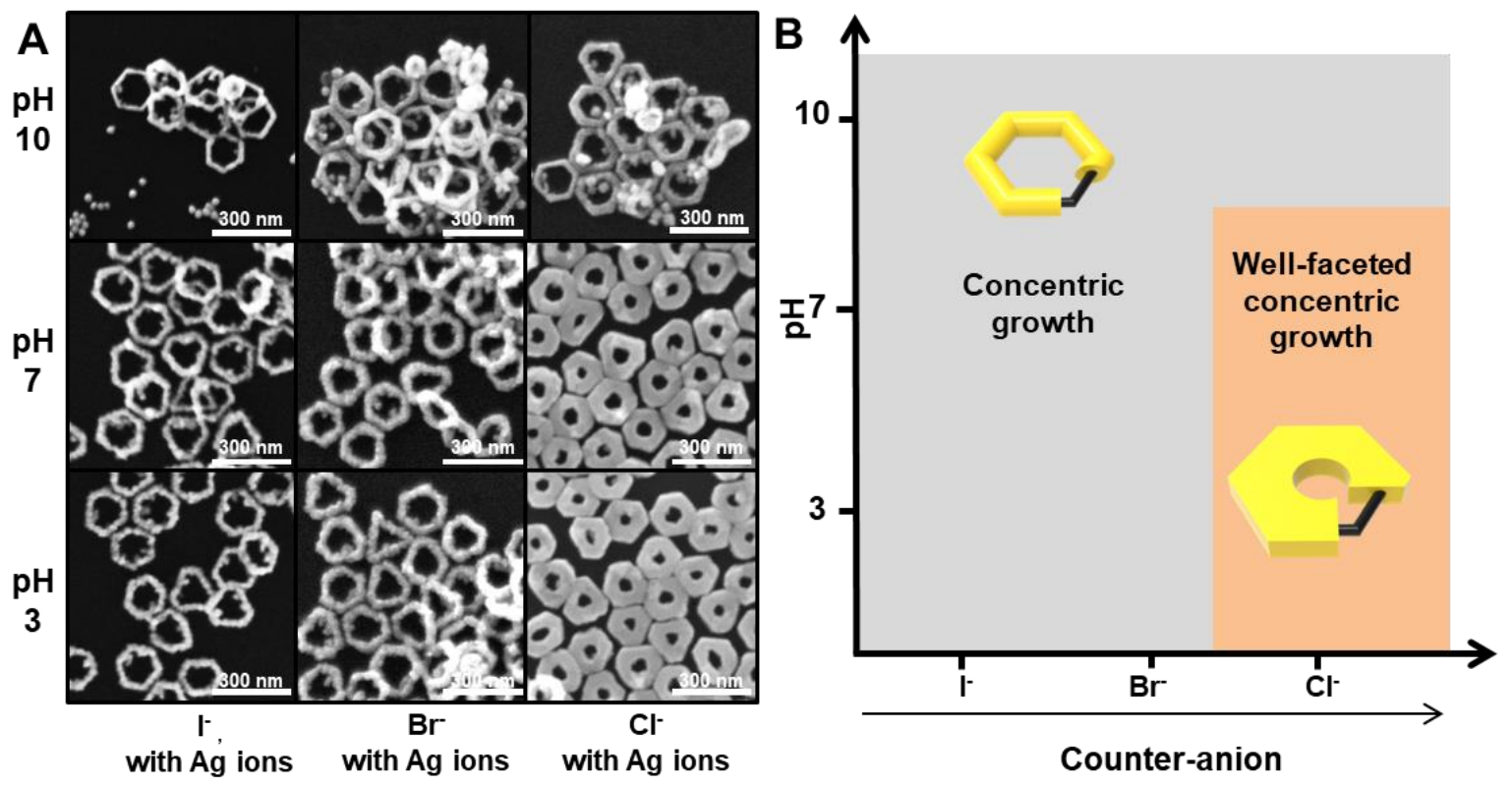

Figure S5. Controlling the growth pattern of Au on the PtAu nanorings by controlling experimental parameters such as pH of the reaction solution and halide ions (I-, Br-, Cl-). (A) FE-SEM images of morphology of Pt@Au nanorings as function of $\mathrm{pH}$ of the reaction solution and halide ions. (B) Summarized experimental conditions for growth pattern control of $\mathrm{Au}$ 


\section{Increasing $[\mathrm{Au}] /[\mathrm{Ag}]$ ratio}
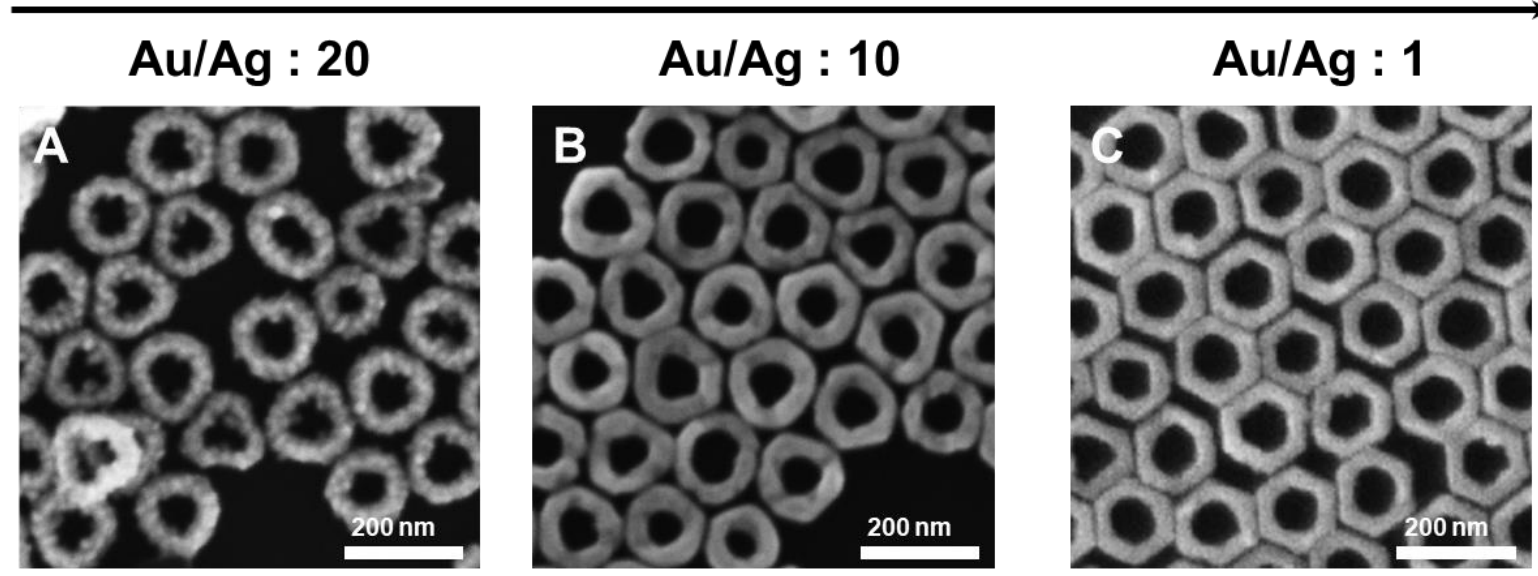

\section{D}

1) Formation of the Ag UPD layer
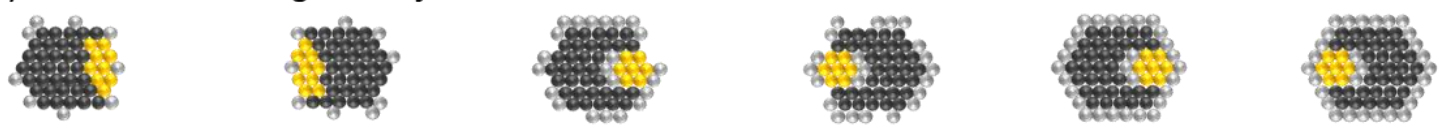

2) Depositing Au
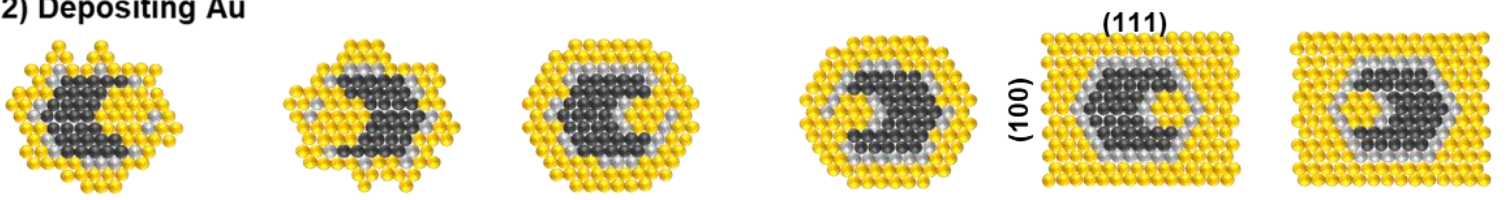

Figure S6. Controlling the morphology of (A to C) Pt@Au nanorings as function of the ratio of $[\mathrm{Au}] /[\mathrm{Ag}] \mathrm{ratio}$. (D) schematic illustration fort mechanism of Au deposition as function of $[\mathrm{Au}] /[\mathrm{Ag}]$ ratio. 


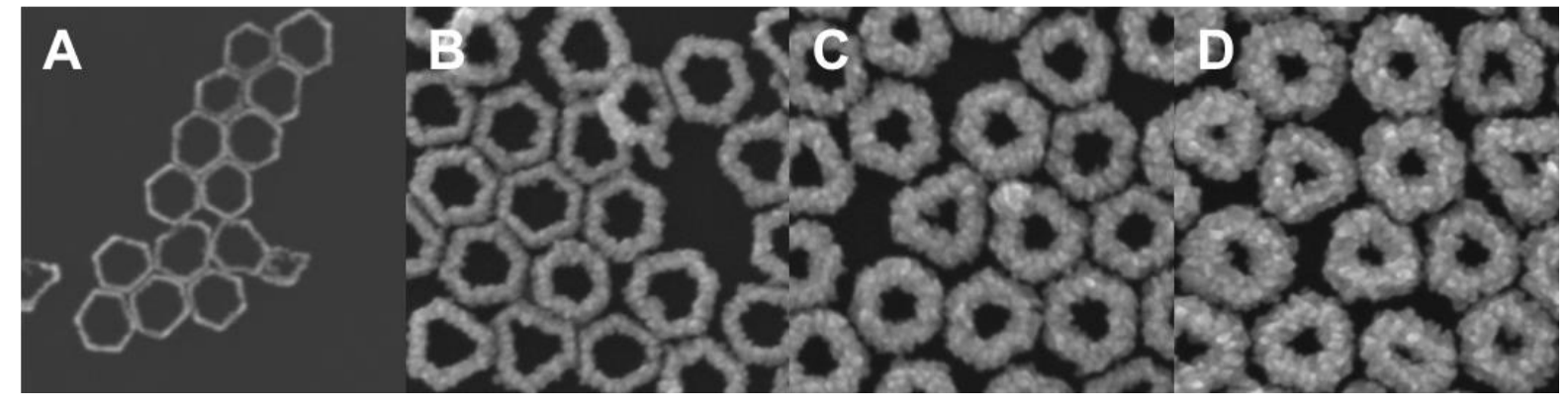

Figure S7. Concentric growth of Au on the (A) PtAu nanorings. (B to D) thickness of Pt@Au nanorings was controlled as a function of the amount of $\mathrm{Au}$ in the reaction solution. 

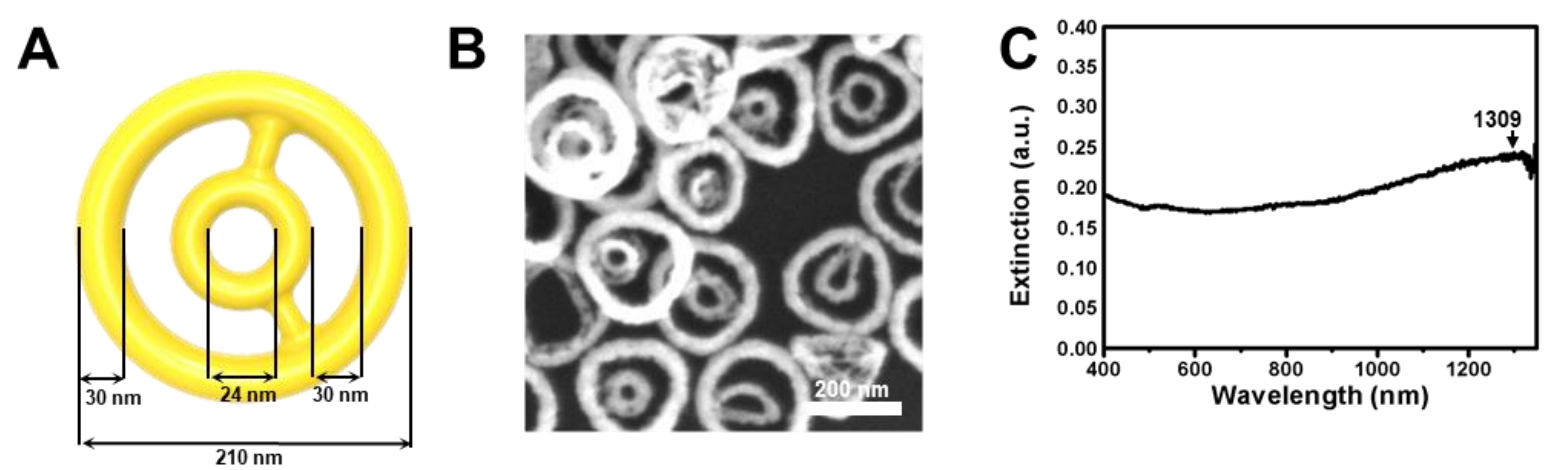

D

E

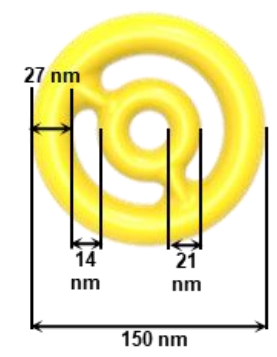

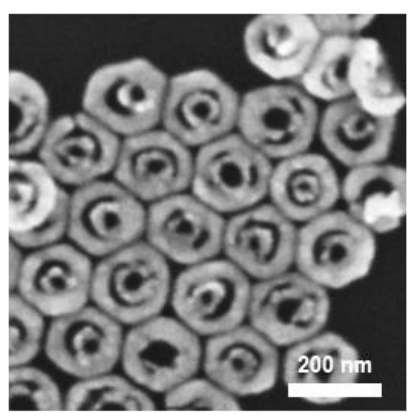

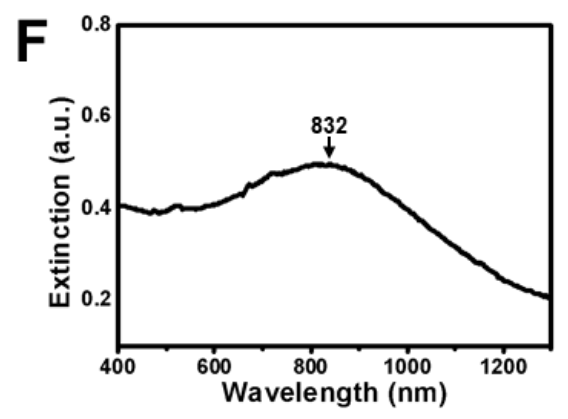

Figure S8. (A and D) Dimension information, (B and E) SEM images, and (C and F) UV-vis-NIR spectra of Au double nanorings with different geometries. 
A

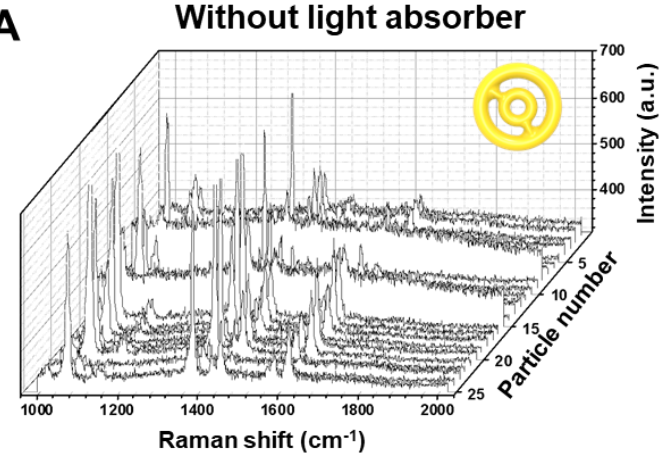

B

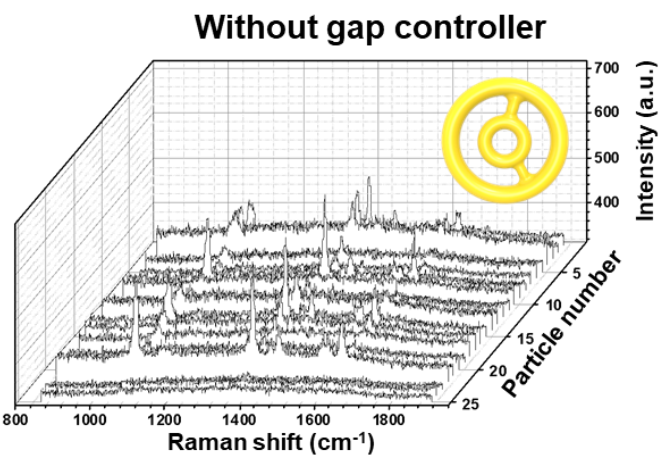

Figure S9. Single-particle SERS signals of double nanorings without (A) light absorber and (B) gap controller. 

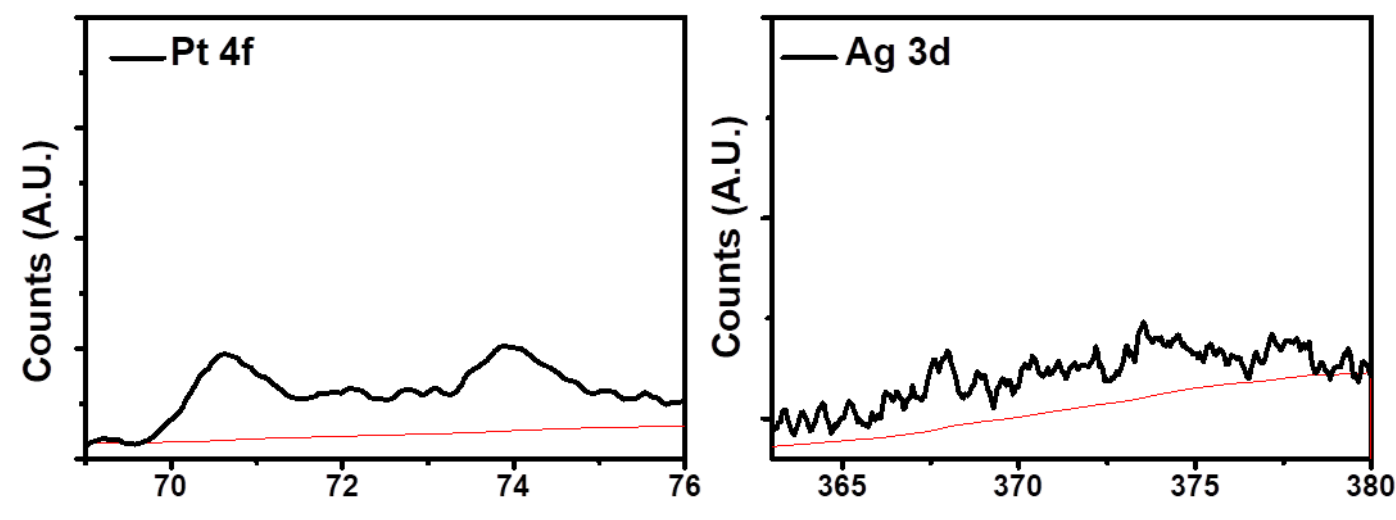

Bind Energy (eV)

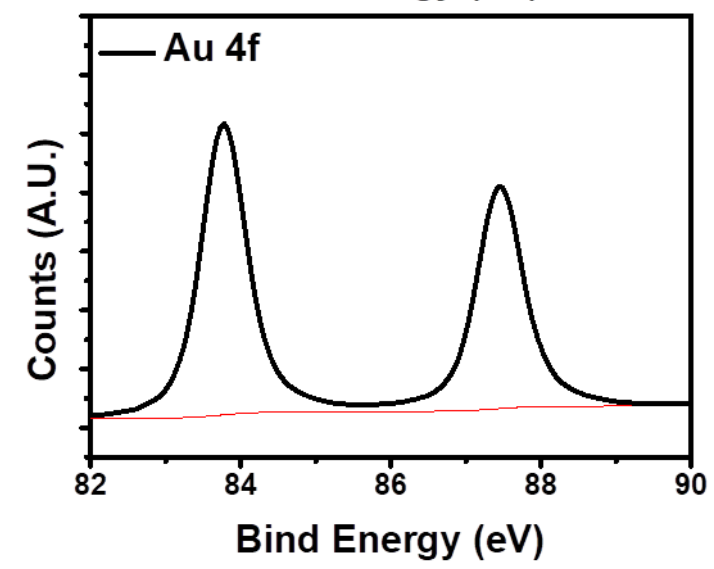

\begin{tabular}{|c|c|c|c|}
\hline Name & Peak BE & FWHM eV & Atomic \% \\
\hline Au 4f & 83.77 & 0.68 & 92.35 \\
\hline Ag 3d & 373.5 & 0.17 & 3.41 \\
\hline Pt 4f & 73.93 & 1.54 & 4.25 \\
\hline
\end{tabular}

Figure S10. Analysis of the surface composition of ANITs (corresponding to Figure 3C) through X-ray photoelectron spectroscopy (XPS). 


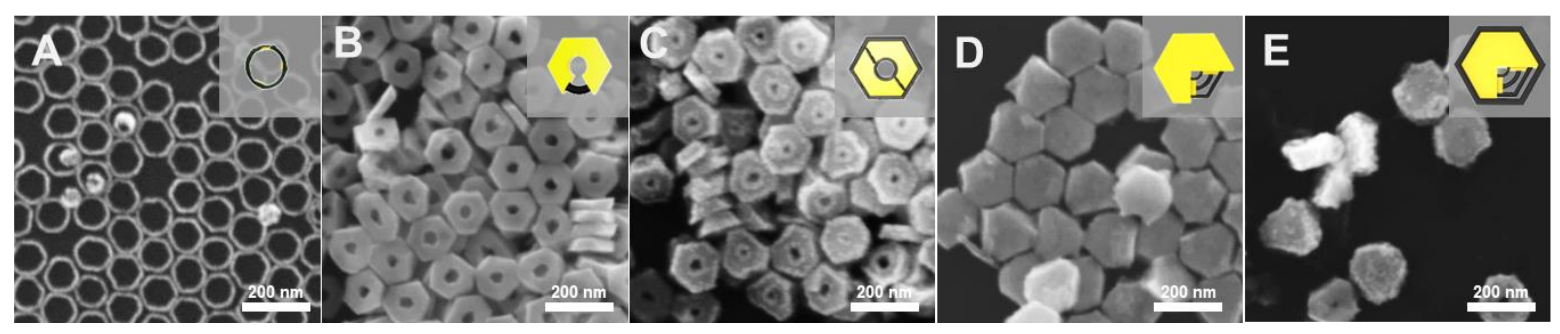

Figure S11. SEM images of (A) PtAu nanorings, (B) Pt@Au nanorings with well-faceted growth, (C) Pt@Au@Pt nanorings, (D)Pt@Au@Pt@Au nanoplates, (E)Pt@Au@Pt@Au@Pt nanoplates. 


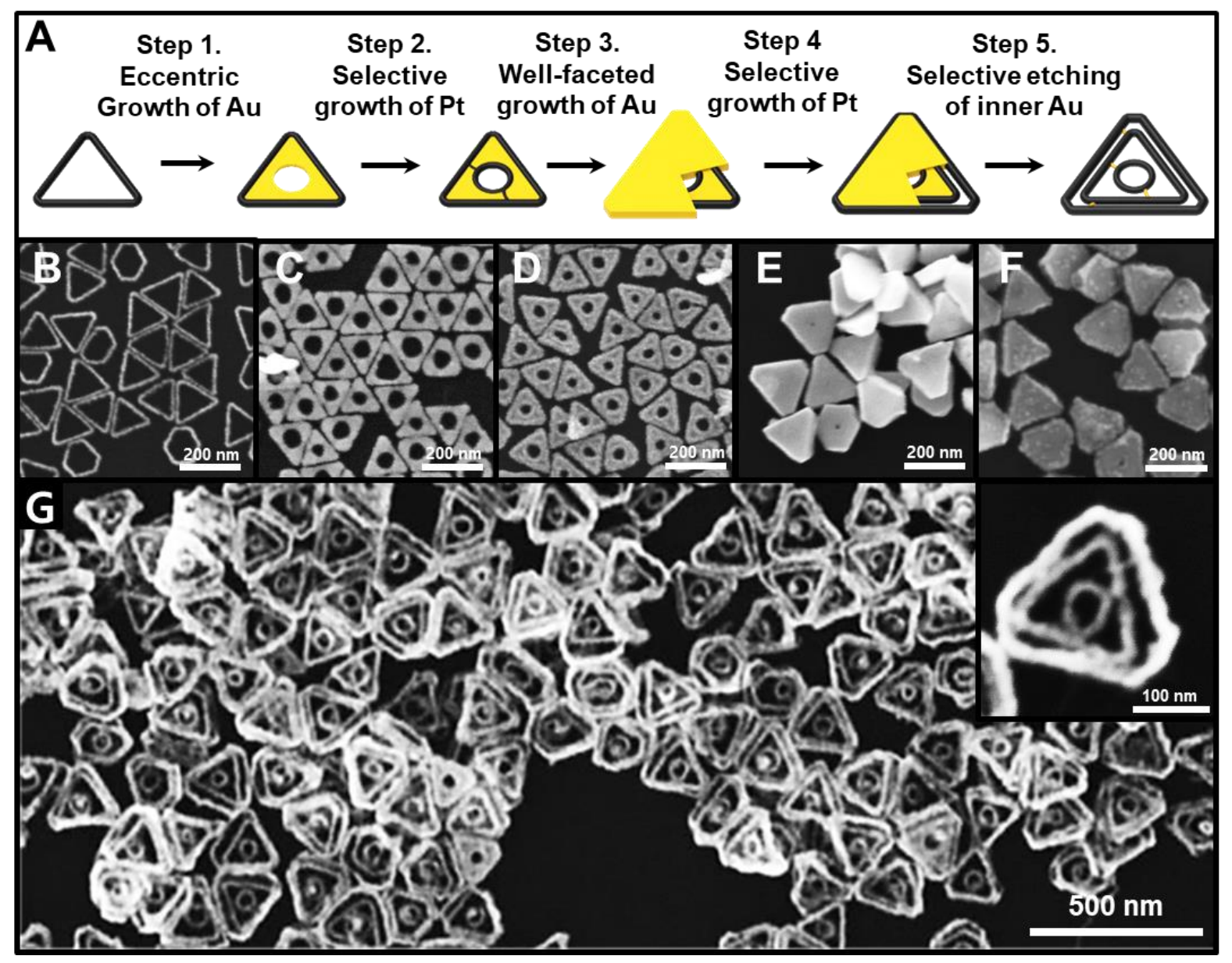

Figure S12. (A) Synthetic process for triangular PtAu triple nanorings, (B) triangular PtAu nanorings, (C) triangularPt@Au nanorings with eccentric growth pattern, (D) triangularPt@Au@Pt nanorings, (E) triangular Pt@Au@Pt@Au nanoplates, (F) triangularPt@Au@Pt@Au nanoplates, and (G) low magnification SEM image and zoomed-in SEM image of triangular PtAu triple nanorings. 